\title{
DIMETILSULFÓXIDO - DMSO NO TESTE DE SENSIBILIDADE MICROBIANA in vitro EM CEPAS DE Rhodococcus equi ISOLADAS DE AFECÇÕES PULMONARES EM POTROS
}

\author{
In vitro EFFECT OF DIMETHYL SULFOXIDE - DMSO IN ANTIMICROBIAL SUSCEPTIBILITY \\ TEST OF Rhodococcus equi ISOLATED FROM PULMONARY INFECTIONS IN FOALS
}

\author{
Márcio Garcia Ribeiro $^{1}$ Aldo Santana de Carvalho Filho ${ }^{2}$ Fernando José Paganini Listoni $^{3}$
}

\section{- NOTA -}

RESUMO

Comparou-se a sensibilidade microbiana in vitro de isolados de Rhodococcus equi pelo teste padrão de difusão com discos, com o modificado, pela adição de $5 \%$ de dimetilsulfóxidoDMSO. Observou-se aumento da sensibilidade do $\boldsymbol{R}$. equi no teste com DMSO, frente a aminoglicosídeos (canamicina, amicacina, estreptomicina) e ao cloranfenicol, enquanto para a eritromicina e derivados $\beta$-lactâmicos (penicilina $G$, cefalosporinas, amoxicilina, oxacilina), constatou-se redução da sensibilidade do agente.

Palavras-chave: Rhodococcus equi, sensibilidade microbiana, dimetilsulfóxido, afecções pulmonares em potros.

\section{SUMMARY}

In vitro antimicrobial susceptibility of strains of Rhodococcus equi by standard diffusion disk test and a modified method, by the addition dimethyl sulphoxide (5\%), was evaluated. Increase in sensitivity of $\boldsymbol{R}$. equi using modified method was observed in aminoglycosides group (kanamycin, amikacin, streptomycin) and cloramphenicol, while erythromycin and $\beta$ lactam derivates (penicillin $G$, cephalosporins, amoxicillin, oxacillin) showed a reduction in sensitivity to the agent.

Key words: Rhodococcus equi, antimicrobial susceptibility test, dimethyl sulphoxide, pneumonia in foals.
Rhodococcus equi (R. equi) é reconhecido como patógeno de distribuição mundial, intracelular facultativo, oportunista, relacionado a afecções de difícil tratamento no homem e animais (LINDER, 1997). No homem, as infecções por $\boldsymbol{R}$. equi têm sido descritas em indivíduos severamente comprometidos, como convalescentes de transplantes, pacientes com neoplasias malignas, sob terapia imunossupressiva, acometidos pela síndrome da imunodeficiência adquirida-AIDS (MOSSER \& HONDALUS, 1996), ou mesmo em indivíduos saudáveis, especialmente crianças (MACGOWAN \& MANGANO, 1991). Nos animais, o $\boldsymbol{R}$. equi é considerado o principal agente etiológico no desenvolvimento de pneumonia em potros (GIGUÈRE \& PRESCOT, 1997).

As limitações no sucesso da terapia antimicrobiana do $\boldsymbol{R}$. equi têm gerado nos últimos, anos, estudos de sensibilidade in vitro do agente, mediante ensaios com novas drogas (GIGUĖRE \& PRESCOT, 1997; PRONOST et al., 1997), bem como a associação de antimicrobianos com substâncias permeabilizantes de membranas celulares, como o dimetilsulfóxido-DMSO (POOTZ et al., 1967). O DMSO é um produto com mais de

${ }^{1}$ Disciplina de Enfermidades Infecciosas dos Animais, Departamento de Higiene Veterinária e Saúde Pública (DHVSP), Faculdade de Medicina Veterinária e Zootecnia (FMVZ), Universidade Estadual Paulista (UNESP), CP 560, 18618-000, Botucatu-SP. E-mail: mgribeiro@fmvz.unesp.br. Autor para correspondência.

${ }^{2}$ Acadêmico de Medicina Veterinária - FMVZ - UNESP/Botucatu-SP, Bolsista de Iniciação Científica-Programa PIBIC - CNPq UNESP.

${ }^{3}$ Auxiliar técnico - DHVSP - FMVZ - UNESP/Botucatu-SP 
30 ações farmacológicas primárias, de baixa toxicidade, empregado há várias décadas em medicina humana e veterinária (JACOB, 1982; ALVES, 1998). A ação permeante de membranas biológicas do DMSO (JACOB, 1982) tem permitido a sua utilização como potencializador de drogas antibacterianas, antifúngicas, antivirais e antiparasitárias (POOTZ et al., 1967; BRAYTON, 1986). Considerando a refratariedade do $\boldsymbol{R}$. equi à terapia com antimicrobianos convencionais, o presente estudo objetivou investigar a sensibilidade microbiana in vitro em isolados do agente, de origem animal, no teste padrão de difusão com discos, comparativamente ao método modificado, pela adição do DMSO.

Foram utilizados 30 isolados de Rhodococcus equi oriundos de afecções pulmonares em potros, obtidos do material de Diagnóstico Microbiológico da FMVZ-UNESP/Botucatu-SP; da Universidade Federal de Santa Maria-RS e da Coleção de Culturas do Instituto Adolfo Lutz de São Paulo-SP, bem como duas cepas padrão de $\boldsymbol{R}$. equi (ATCC 33.701 - e ATCC $33.701+$ ), cedidas pelo Instituto de Biociências da UNESP/Botucatu-SP, provenientes da Faculdade de Medicina Veterinária de Ontário (Guelph), Canadá; totalizando a avaliação de 32 cepas de $\boldsymbol{R}$. equi.

Os 30 isolados de $\boldsymbol{R}$. equi e as duas cepas ATCC foram submetidos ao teste padrão de sensibilidade microbiana in vitro, pelo método de difusão com discos (BAUER et al., 1966), e ao modificado, pela adição do DMSO a $5 \%$, não autoclavado (CORRÊA \& CORRÊA, 1992), frente a 26 antimicrobianos (Tabela 1). O DMSO (puro para análise-Synth) foi adicionado assepticamente ao meio de Müller-Hinton, após a autoclavação e resfriamento do meio, antes da disposição nas placas de Petri. Em cinco dos isolados de $\boldsymbol{R}$. equi (incluindo as duas ATCC), realizou-se o teste modificado com o DMSO a $10 \%$ e $20 \%$.

A análise estatística foi realizada mediante a comparação entre duas proporções com amostras dependentes, pelo teste de $\chi^{2}$ de McNemar (CURI, 1997), considerando diferença significante para valores de $\mathrm{P}<0,05$

Os maiores índices de sensibilidade do $\boldsymbol{R}$. equi na prova padrão foram observados para a eritromicina $(100,0 \%)$, vancomicina $(100,0 \%)$, rifampicina $(97,0 \%)$ e neomicina $(94,0 \%)$ (Tabela 1). Em medicina veterinária, a associação entre rifampicina e eritromicina tem sido apontada como a terapia de eleição para a rodococose pulmonar (PRONOST et al., 1998). A alta sensibilidade in vitro do $\boldsymbol{R}$. equi à eritromicina e a rifampicina verificada no presente estudo, ratifica a condição destas drogas, como de primeira escolha na indicação terapêutica de afecções pulmonares pelo $\boldsymbol{R}$. equi em potros. Entretanto, de maneira geral, observaram-se altos índices de resistência do agente, especialmente para os derivados $\beta$-lactâmicos (Tabela 1). Este resultado concorda com os obtidos por PRESCOTT (1991) e GIGUÈRE \& PRESCOTT (1997), cujos estudos também evidenciaram alta resistência do $\boldsymbol{R}$. equi em ensaios de sensibilidade in vitro frente a antimicrobianos convencionais.

No método modificado com o DMSO, observou-se, no presente estudo, aumento estatisticamente significante $(\mathrm{P}<0,05) \quad$ da sensibilidade do $\boldsymbol{R}$. equi para canamicina, amicacina, estreptomicina e cloranfenicol, além do acréscimo na efetividade de outras drogas (enrofloxacina, ciprofloxacina, doxiciclina e gentamicina). CORRÊA et al. (1981) investigando o mesmo método em microrganismos isolados de mastite bovina, também concluíram que a adição do DMSO favoreceu a ação in vitro do cloranfenicol, estreptomicina, neomicina e furadantina. $\mathrm{O}$ mecanismo de ação dos aminoglicosídeos e do cloranfenicol depende, fundamentalmente, da veiculação dos princípios ativos para o interior dos microrganismos, proporcionando a atuação destas drogas no ribosssoma bacteriano (TAVARES, 1996). No presente estudo, a propriedade permeante de membranas biológicas atribuídas ao DMSO (JACOB, 1982), pode ter favorecido a difusão dos aminoglicosídeos e do cloranfenicol pela parede bacteriana do $\boldsymbol{R}$. equi, otimizando o mecanismo de ação destas drogas, resultando no incremento da sensibilidade do agente.

Ainda que a adição do DMSO tenha favorecido a sensibilidade in vitro do único isolado de $\boldsymbol{R}$. equi resistente à rifampicina, em contrapartida, constatou-se $41 \%$ de redução na sensibilidade do agente à eritromicina, bem como redução na efetividade dos derivados ß-lactâmicos (com exceção do imipeném) (Tabela 1). WOOD \& WOOD (1975) já haviam alertado para esse efeito, embora não esclarecessem se seria decorrente da estimulação e/ou favorecimento do DMSO à produção de enzimas pelos microrganismos (semelhantes às ß-lactamases), que inativassem a ação de determinados antimicrobianos. Estes resultados alertam para a limitação da indicação do DMSO no tratamento antimicrobiano de eleição da rodococose em potros (associação entre rifampicina e eritromicina), em virtude da possível redução na atividade da eritromicina.

Não foi possível a avaliação in vitro do DMSO a 10 e a $20 \%$, em virtude da ausência de crescimento dos cinco isolados de $\boldsymbol{R}$. equi nestas 
Tabela 1 - Sensibilidade microbiana em isolados de Rhodococcus equi na prova padrão de difusão com discos e na modificada, pela adição do dimetilsulfóxido-DMSO.

\begin{tabular}{|c|c|c|c|c|c|c|}
\hline \multirow{3}{*}{$\begin{array}{l}\text { ANTIMICROBIANOS } \\
\text { (concentração da droga) }\end{array}$} & \multicolumn{3}{|c|}{$\begin{array}{l}\text { Sensibilidade } \\
\text { sem DMSO }\end{array}$} & \multicolumn{3}{|c|}{$\begin{array}{l}\text { Sensibilidade } \\
\text { com DMSO }\end{array}$} \\
\hline & & $\begin{array}{l}\text { No. de isolados } \\
\text { sensíveis / } \\
\text { No. de isolados } \\
\text { testados (\%) }\end{array}$ & & & $\begin{array}{l}\text { No. de isolados } \\
\text { sensíveis / } \\
\text { No. de isolados } \\
\text { testados }(\%)\end{array}$ & \\
\hline & sensível & intermediária & resistente & sensível & intermediária & resistente \\
\hline Amicacina (30mcg) & $19 / 32(59)$ & $9 / 32(28)$ & $4 / 32(13)$ & $31 / 32(97)$ & $1 / 32(3)$ & $0 / 32(0)$ \\
\hline Amoxicilina (10mcg) & $3 / 32(9)$ & $0 / 32(0)$ & $29 / 32(91)$ & $1 / 32(3)$ & $1 / 32(3)$ & $30 / 32(94)$ \\
\hline Amox./Ác. Clav. (30mcg) & $22 / 32(68)$ & 6/32 (19) & 4/32 (13) & $2 / 32(6)$ & $14 / 32(44)$ & $16 / 32(50)$ \\
\hline Ampicilina (10mcg) & 4/32 (13) & $5 / 32(16)$ & $23 / 32(71)$ & 4/32 (13) & $7 / 32(22)$ & $21 / 32(65)$ \\
\hline Canamicina (30mcg) & $0 / 32(0)$ & $10 / 32(31)$ & $22 / 32(69)$ & $16 / 32(50)$ & $15 / 32(47)$ & $1 / 32(3)$ \\
\hline Cefalexina $(30 \mathrm{mcg})$ & $0 / 32(0)$ & $0 / 32(0)$ & $32 / 32(100)$ & $0 / 32(0)$ & $0 / 32(0)$ & $32 / 32(100)$ \\
\hline Cefalotina (30mcg) & $1 / 32(3)$ & $0 / 32(0)$ & $31 / 32(97)$ & $0 / 32(0)$ & $0 / 32(0)$ & $32 / 32(100)$ \\
\hline Cefazolina (30mcg) & $3 / 32(9)$ & $1 / 32(3)$ & $28 / 32(88)$ & $2 / 32(6)$ & $0 / 32(0)$ & $30 / 32(94)$ \\
\hline Cefotaxima (30mcg) & $7 / 32(22)$ & $11 / 32(34)$ & $14 / 32(44)$ & $2 / 32(6)$ & $0 / 32(0)$ & $30 / 32(94)$ \\
\hline Ciprofloxacina (5mcg) & $21 / 32(66)$ & $10 / 32(31)$ & $1 / 32(3)$ & $25 / 32(78)$ & 6/32 (19) & $1 / 32(3)$ \\
\hline Cloranfenicol (30mcg) & $7 / 32(22)$ & $19 / 32(59)$ & $6 / 32(19)$ & $15 / 32(47)$ & $14 / 32(44)$ & $3 / 32(9)$ \\
\hline Doxiciclina (30mcg) & $27 / 32(84)$ & 4/32 (13) & $1 / 32(3)$ & $30 / 32(94)$ & $2 / 32(6)$ & $0 / 32(0)$ \\
\hline Enrofloxacina $(5 \mathrm{mcg})$ & $11 / 32(34)$ & $18 / 32(57)$ & $3 / 32(9)$ & $17 / 32(53)$ & $13 / 32(41)$ & $2 / 32(6)$ \\
\hline Eritromicina $(15 \mathrm{mcg})$ & $32 / 32(100)$ & $0 / 32(0)$ & $0 / 32(0)$ & $19 / 32(59)$ & $13 / 32(41)$ & $0 / 32(0)$ \\
\hline Estreptomicina (10mcg) & $18 / 32(56)$ & $7 / 32(22)$ & $7 / 32(22)$ & $30 / 32(94)$ & $2 / 32(6)$ & $0 / 32(0)$ \\
\hline Gentamicina (10mcg) & $29 / 32(91)$ & $2 / 32(6)$ & $1 / 32(3)$ & $32 / 32(100)$ & $0 / 32(0)$ & $0 / 32(0)$ \\
\hline Imipeném (10mcg) & $27 / 32(84)$ & $0 / 32(0)$ & $5 / 32(16)$ & $28 / 32(87)$ & $0 / 32(0)$ & 4/32 (13) \\
\hline Lincomicina ( $2 \mathrm{mcg})$ & $0 / 32(0)$ & $0 / 32(0)$ & $32 / 32(100)$ & $0 / 32(0)$ & $0 / 32(0)$ & $32 / 32(100)$ \\
\hline Metronidazole (50mcg) & $0 / 32(0)$ & $0 / 32(0)$ & $32 / 32(100)$ & $0 / 32(0)$ & $0 / 32(0)$ & $32 / 32(100)$ \\
\hline Neomicina $(30 \mathrm{mcg})$ & $30 / 32(94)$ & $0 / 32(0)$ & $2 / 32(6)$ & $32 / 32(100)$ & $0 / 32(0)$ & $0 / 32(0)$ \\
\hline Oxacilina (5mcg) & $1 / 32(3)$ & $0 / 32(0)$ & $31 / 32(97)$ & $0 / 32(0)$ & $0 / 32(0)$ & $32 / 32(100)$ \\
\hline Penicilina G (10UI) & $1 / 32(3)$ & $0 / 32(0)$ & $31 / 32(97)$ & $0 / 32(0)$ & $0 / 32(0)$ & $32 / 32(100)$ \\
\hline Rifampicina (5mcg) & $31 / 32(97)$ & $0 / 32(0)$ & $1 / 32(3)$ & $32 / 32(100)$ & $0 / 32(0)$ & $0 / 32(0)$ \\
\hline Sulfa/Trimetoprim (25mcg) & $0 / 32(0)$ & $5 / 32(16)$ & $27 / 32(84)$ & $2 / 32(6)$ & $0 / 32(0)$ & $30 / 32(94)$ \\
\hline Tetraciclina (30mcg) & $2 / 32(6)$ & $18 / 32(56)$ & $12 / 32(38)$ & $0 / 32(0)$ & $10 / 32(31)$ & 22/32 (69) \\
\hline Vancomicina (30mcg) & $32 / 32(100)$ & $0 / 32(0)$ & $0 / 32(0)$ & $32 / 32(100)$ & $0 / 32(0)$ & $0 / 32(0)$ \\
\hline
\end{tabular}

mcg $=$ microgramas $\quad$ No. $=$ número de cepas Sulfadiazina

concentrações da droga. Estes dados discordam dos obtidos por CORREAA et al. (1981), que empregaram o DMSO a $20 \%$ na técnica de difusão com discos, frente a outros microrganismos. Entretanto, posteriormente, CORRÊA \& CORRÊA (1992) assinalaram inibição do crescimento de microrganismos nesta concentração, provavelmente pela atividade bacteriostática ou bactericida do produto a $20 \%$, sugerindo a sua utilização a $5 \%$ no teste modificado in vitro.

Para as drogas de aplicação em medicina humana na terapia do $\boldsymbol{R}$. equi, observou-se alta sensibilidade do agente para vancomicina, doxiciclina e imipeném, superiores respectivamente, a $84 \%$ e $88 \%$, sem e com a adição do DMSO (Tabela 1). Apesar da efetividade in vitro destas drogas, o seu uso em humanos não tem surtido efeito clínico satisfatório (SAMIES et al., 1986), resultado que, aliado ao custo e à apresentação somente para a linha humana tem, provavelmente, impossibilitado seu uso em eqüinos.

Denota-se no presente estudo, aumento na sensibilidade in vitro dos isolados de $\boldsymbol{R}$. equi na prova modificada com o DMSO, para o grupo dos aminoglicosídeos e para o cloranfenicol, provavelmente pelo incremento na difusão destas drogas pela parede bacteriana, favorecendo o mecanismo de ação destes antimicrobianos. Estes 
resultados sugerem estudos da eficácia destas drogas em associação ao DMSO nas infecções por $\boldsymbol{R}$. equi em potros, visando protocolos terapêuticos alternativos para a rodococose equina. Entretanto, alerta-se para restrições na utilização de drogas que apresentaram redução da eficiência in vitro quando associadas ao DMSO, como os derivados Blactâmicos, e principalmente, a eritromicina, considerada de eleição na terapia da rodococose eqüina.

\section{AGRADECIMENTOS}

À Profa. Dra. Agueda Castagna de Vargas da UFSMRS e ao Prof. Dr. Antônio Carlos Paes da FMVZ UNESP/Botucatu-SP, bem como a Coleção de Culturas do Instituto Adolfo Lutz de São Paulo-SP, pela cessão de isolados de R. equi; e ao Instituto de Biociências da UNESP/Botucatu-SP pelas cepas ATCC de $\boldsymbol{R}$. equi.

\section{REFERÊNCIAS BIBLIOGRÁFICAS}

ALVES, G.E.S. Dimetilsulfóxido (DMSO). Saúde Eqüina, n.6 p.6-10, 1998

BAUER, A.W., KIRBY, W.M.M., SHERRIS, J.C., et al. Antibiotic susceptibility testing by a standardized single disk method. American Journal of Clinical Pathology, v.45, p.493-496, 1966

BRAYTON, C.F. Dimethyl sulfoxide (DMSO): a review. Cornell Vet., v.76, p.61-90, 1986.

CORRÊA, W.M., CORRÊA, C.N.M. Enfermidades infecciosas dos mamíferos domésticos. 2.ed. Rio de Janeiro : Medsi, 1992 Mastites: p.117-131

CORRÊA, W.M., CORRÊA, C.N.M., LANGONI, H., et al. Ensaio "in vitro" de drogas antibacterianas e associadas ao dimetil sulfóxido (DMSO). Arq Esc Vet UFMG, Belo Horizonte, v.33, p.449-453, 1981.

CURI, P.R. Metodologia e análise da pesquisa em ciências biológicas. Botucatu : Tipomic, 1997. 263p.
GIGUÈRE, S., PRESCOTT, J.F. Clinical manifestations, diagnosis, treatment, and prevention of Rhodococcus equi infections in foals. Veterinary Microbiology, v.56, p.313334, 1997.

JACOB, S. DMSO. Mode of action and biologic effects. Veterinary Medicine, p.365-376, 1982.

LINDER, R. Rhodococcus equi and Corynebacterium haemolyticum: Two "Coryneform" bacteria increasingly recognized as agents of human infection. Emerging Infectiuos Diseases, v.3, p.1-10, 1997.

MACGOWAN, K.L., MANGANO, M.F. Infections on Rhodococcus equi in children. Diagn Microbiol Infect Dis, v.14, p.347-352, 1991.

MOSSER, D.M., HONDALUS, M.K. Rhodococcus equi: an emerging opportunistic pathogen. Trends in Microbiology, v.4, p.29-33, 1996.

POOTZ, G., RAMPEY, J.H., BENJAMIN, F. The effect of dimethyl sulfoxide (DMSO) in antibiotic sensitivity of a group of medically important microorganisms. A preliminary report. Annales of New York Academic Press, v.141, p.261-272, 1967

PRESCOTT, J.F. Rhodococcus equi: an animal and human pathogen. Clinical Microbiology Reviews, v.4, p.20-34, 1991.

PRONOST, S., FORTIER, G., LEGENDRE, M.F., et al. Rhodococcus équine: nouvelles approches et bilan de trois annnées d'études au laboratoire. Prat Vét Equine, v.30, p.57-65, 1998.

SAMIES, J.H., HATHAWAY, B.N., ECHOLS, R.M., et al. Lung abscess due to Corynebacterium equi. Report of the first case in a patient with acquired immunodeficiency syndrome. Am J Med, v.80, p.685-688, 1986

TAVARES, W. Manual de antibióticos e quimioterápicos antiinfecciosos. 2.ed. São Paulo: Atheneu, 1996. 792p.

WOOD, D.C., WOOD, J. Pharmacologic and biochemica considerations of dimethyl sulfoxide. Ann N Y Acad Sci, v. 243, p.7-19, 1975

Ciência Rural, v. 31, n. 5, 2001. 